\title{
Phytochemical Analysis, Total Phenolic Content, Antioxidant and Antidiabetic Activity of Sansevieria cylindrica Leaves Extract
}

\author{
Tanveer $A^{1}$, Devendra Singh $\mathbf{N}^{2}$ and Faheem Khan $\mathbf{M}^{1 *}$ \\ ${ }^{1}$ Department of Biotechnology, Era's Lucknow Medical College and Hospital, Sarfarazganj, Lucknow, Uttar Pradesh, India \\ ${ }^{2}$ Department of Chemistry, HNB Garhwal University, Srinagar, Uttarakhand, India
}

${ }^{*}$ Corresponding author: Faheem Khan M, Department of Biotechnology, Era's Lucknow Medical College and Hospital, Sarfarazganj, Lucknow, Uttar Pradesh, India, Tel: +917800737252; E-mail: faheemkhan35@gmail.com

Received date: June 22, 2017; Accepted date: June 26, 2017; Published date: June 30, 2017

Copyright: (C) 2017 Tanveer A, et al. This is an open-access article distributed under the terms of the Creative Commons Attribution License, which permits unrestricted use, distribution, and reproduction in any medium, provided the original author and source are credited.

Citation: Tanveer A, Devendra Singh N, Faheem Khan M. Phytochemical Analysis, Total Phenolic Content, Antioxidant and Antidiabetic Activity of Sansevieria cylindrica Leaves Extract. Herb Med. 2017, Vol.3 No:2:6.

\begin{abstract}
Background: Genus "Sansevieria" has been traditionally used for the treatment of various ailments in African countries since a long time. In particular, Sansevieria trifasciata is used for the treatment of inflammatory conditions and sold as a crude drug in the market to treat victims of snakebite in South Africa and tropical America. Therefore, the present study aimed to investigate the presence of phytochemicals, total phenolic content, antioxidant as well as antidiabetic activity of ethanol extract and fractions of Sansevieria cylindrica leaves.
\end{abstract}

Methods and findings: Phytochemical analysis of hexane, chloroform, methanol and aqueous fractions Sansevieria cylindrica leaves confirmed the presence of steroids, flavonoids, saponins, tannins, and phenolic acids. Methanol fraction was found to show maximum phenolic content. Ethanol extract and its methanol fraction showed significant antioxidant and antidiabetic activity. They inhibited $80.5 \%$ and $83.6 \%$ respectively DPPH free radical at $100 \mu \mathrm{g} / \mathrm{ml}$ concentration. In addition, methanol fraction exhibited $57.9 \%$ inhibition of glucose-6phosphatase enzyme at $100 \mu \mathrm{M}$ concentration.

Conclusion: Our study confirmed the traditional uses of Sansevieria cylindrica plants for the treatment of various diseases.

Keywords: Sansevieria cylindrica; Phytochemical analysis; Total phenolic content; Antioxidant activity; Antidiabetic activity

\section{Introduction}

Medicinal plants have been identified as herbal medicine and used all over world from prehistoric times [1]. These medicines refers to using a plant's seeds, berries, roots, leaves, bark, or flowers for medicinal purposes. Plants as medicine provides significant advantages for treatment of many illness conditions. The therapeutic activity of a plant is due to presence of complex chemical constituents in different parts providing certain therapeutic effects [2]. World Health Organization (WHO) estimated that $80 \%$ of people worldwide rely on herbal medicines with increasingly interest because of public dissatisfaction with the cost of prescribe medications, various side effects of synthetic medicines, non-toxic nature, more affordable with lower cost and allows greater public access to health information [3]. Plants are rich sources of different types of secondary metabolites which are generally termed as compounds. These compounds not only used directly as therapeutic agents, but also as starting materials for the synthesis of drugs or as models for pharmacologically active compounds [4]. Many of these compounds have pharmacological activities and used in the treatment of chronic and acute conditions and various ailments such as cardiovascular disease, prostate problems, depression, inflammation, to boost the immune system and antioxidant properties. Antioxidant activity is shown by phenols or their oxygen-substituted derivatives such as tannins, flavonoids, phenolic acid as well as compounds having hydroxyl functionality [5]. Based on the traditional aspects of herbal medicine, this study was conducted to evaluate the antioxidant as well as antidiabetic activity of leave extracts of Sansevieria cylindrica.

Sansevieria cylindrica (SC) belongs to the family Asparagaceae, commonly referred to as Spear Sansevieria. It is a succulent and evergreen perennial plant native to the subtropical regions of the African continent and cultivated in Egypt for ornamental purposes [6]. It is also found in some part of India as ornamental plant. SC including other species have different chemical constituents such as dicarboxylic acids, phenols, steroidal saponins, saponins, homoisoflavanone, coumarins and ester of fatty acids [7]. Sansevieria species were investigated for many pharmacological activities, such as antimicrobial, antioxidant, antitumor, and antidiabetic activities and inhibition of the capillary permeability activity [8]. However, a survey of the literature showed that no 
antioxidant and antidiabetic activities of leaves of SC have been carried out. As part of our research work on the phytochemical investigation of medicinal plants, we have reported antioxidant and antidiabetic activities of extract and their fractions of leaves SC.

\section{Materials and Methods}

\section{Experimental}

All solvents (Ethanol, methanol, dichloromethane hydrochloric acid, sulfuric acid, chloroform, ammonia, glacial acetic acid, sodium hydroxide) were purchased from SD fine chemical limited, Mumbai, India and were used without further purification. All chemicals were of analytical grade. 1,1Diphenyl-2-picrylhydrazyl (DPPH), Folin-Ciocalteu reagent, gallic acid, ascorbic acid, anhydrous sodium carbonate $\left(\mathrm{Na}_{2} \mathrm{CO}_{3}\right)$, Dragendorff's reagent, mercuric chloride, potassium iodide, iodine were purchased from Sigma-Aldrich, Mumbai, India. Solvents were recovered by using water bath (Perfit India) and Buchi Rotavapor (R-300). Absorbance was measured with the help of UV-VIS spectrophotometer (Systronic, model 059).

\section{Plant material}

SC leaves were collected from botanical garden, Department of Botany, University of Lucknow, Lucknow, UP, India in January 2017. Plant material was kindly confirmed and authenticated Dr. Alka, Department of Botany, University of Lucknow, Lucknow, UP, India where one voucher specimen was deposited. The collected samples were air-dried, powdered and kept in tightly-closed container for further experiment.

\section{Extraction and fractionation}

SC leaves $(1.0 \mathrm{~kg})$ were chopped into small pieces and airdried at room temperature over several days until dryness. The dried pieces were powdered, weighed and percolated with $95 \%$ ethanol. It was repeated five times with interval of 3 days. After percolation, filtration was carried out using Whatman filter paper. The combined filtrate of the alcoholic extracts was concentrated using Buchi Rota vapor (Interface R-300) with the speed set at $150 \mathrm{rpm}$ and temperature at $45^{\circ} \mathrm{C}$. The concentrated extract was removed from the round bottom flask with ethanol and poured into weighed beakers. The alcoholic solvent was allowed to evaporate up to dryness. The dried solid extract was collected, weighed and used for fractionation. The ethanol extract $(50 \mathrm{~g})$ was triturated with hexane $(5.1 \mathrm{~g})$ and the hexane insoluble portion was dissolved in water, which was successively extracted with chloroform $(500 \mathrm{ml} \times 3)$ and methanol $(500 \mathrm{ml} \times 3)$ which yielded fractions of chloroform (12.7 g), methanol (20.5 g) and water (8.2 g).

\section{Phytochemical screening}

Phytochemical screening was carried out for all the extracts and fractions according to the method described by Trease and Evans [9], with slight modifications. The screening was performed for steroids, flavonoids, saponins, tannins, and phenolic acids. The color intensity or the precipitate formation was used as analytical tests. The qualitative results are expressed as (+) for the presence and (-) for the absence of phytochemicals.

\section{Total phenolic content}

Total soluble phenolics of the extracts were determined with FolinCiocalteau reagent with the help of UVVIS spectrophotometer [10]. Gallic acid was used as a standard. One $\mathrm{mg}$ of gallic acid was dissolved in $10 \mathrm{ml}$ of methanol $(100 \mu \mathrm{g} / \mathrm{ml})$ to prepare stock solution and then further diluted to $8,4,2$ and $1 \mu \mathrm{g} / \mathrm{ml}$. one $\mathrm{ml}$ aliquot of each dilution was taken and diluted with $10 \mathrm{ml}$ of distilled water. Then $3 \mathrm{ml}$ Folin-Ciocalteu reagent was added and allowed to incubate at room temperature for $5 \mathrm{~min} 2 \mathrm{ml}$ of $20 \%(\mathrm{w} / \mathrm{w})$ $\mathrm{Na}_{2} \mathrm{CO}_{3}$ was added in each sample and left to stand for $30 \mathrm{~min}$ at room temperature. Absorbance was measured at $765 \mathrm{~nm}$ using UV-VIS spectrophotometer against blank (distilled water). Results were expressed as milligrams of gallic acid equivalent (GAE) per $100 \mathrm{~g}$ of the dry sample. The coefficient of determination was $r=0.9968$.

\section{DPPH assay}

DPPH (1,1-diphenyl-2-picrylhydrazyl) radical scavenging activity was evaluated based on method described previously [11]. It was measured a decrease in absorbance at $517 \mathrm{~nm}$ of a solution of colored DPPH in methanol brought about by the sample. Ascorbic acid was used as reference compound. Briefly, $5 \mathrm{ml}$ of methanol, DPPH $(0.1 \mathrm{mM})$ was added to $1 \mathrm{ml}$ of the sample solution at $5 \mu \mathrm{g} / \mathrm{mL}, 10 \mu \mathrm{g} / \mathrm{mL}, 25 \mu \mathrm{g} / \mathrm{mL}, 50$ $\mu \mathrm{g} / \mathrm{mL}$ and $100 \mu \mathrm{g} / \mathrm{mL}$ concentrations. These mixtures were incubated for $30 \mathrm{~min}$ at room temperature. After this, the absorbance was measured at $517 \mathrm{~nm}$ against a blank. The inhibition of DPPH radical was calculated as follows:

$\%$ Inhibition of DPPH=Abs control $-\mathrm{Abs}_{\text {Sample }} / \mathrm{Abs}_{\text {control }} \times 100$

Where $\mathrm{Abs}_{\text {control }}$ is the absorbance of $\mathrm{DPPH}$ radical +methanol; $\mathrm{Abs}_{\text {sample }}$ is the absorbance of DPPH radical +extract/standard.

\section{D-glucose-6-phosphate phosphorylase (from rat liver) assay}

The livers of male rats of Wistar strain were exercised. A $10 \%$ homogenate was prepared in $150 \mathrm{mM} \mathrm{KCl}$ using Potter Elvejhem glass homogenizer fitted with Teflon pestle. The homogenate was centrifuged at $1500 \mathrm{rpm}$ for $10 \mathrm{~min}$; supernatant was decanted and used as enzyme source. The effect of extract and fractions were studied by pre-incubating the compound in $1.0 \mathrm{~mL}$ reaction system for $15 \mathrm{~min}$ and then determining the residual glucose-6-phosphatase activity according to the method of Hubscher and West [12]. The 1.0 $\mathrm{mL}$ assay system contained $0.3 \mathrm{M}$ citrate buffer ( $\mathrm{pH} 6.0), 28$ mM EDTA, $14 \mathrm{mM} \mathrm{NaF,} 200 \mathrm{mM}$ glucose-6-phosphate, and enzyme protein. The mixture was incubated at $37^{\circ} \mathrm{C}$ for $30 \mathrm{~min}$ after which $1.0 \mathrm{~mL}$ of $10 \%$ TCA was added. Estimation of 
inorganic phosphates $(\mathrm{Pi})$ in protein free supernatant was done according to the method of Taussky and Shorr [13] Glucose-6phosphatase activity was defined as micromole Pi released per minute per milligram protein.

\section{Statistical analysis}

The values are expressed as Means \pm SD. Experiments were repeated three times. Data were analyzed using one way ANOVA followed by Dunnett's test for multiple comparisons using the graph pad prism v5.0 (Graph pad software, inc., USA). $P$ values of less than 0.05 were taken to be significant in the experiments.

\section{Results and Discussion}

\section{Phytochemical screening}

The preliminary phytochemical screening of leaf extracts of SC (Table 1) revealed the presence of various compounds such as phenols, alkaloids, saponins, steroidal-saponin, flavonoids, fatty acids and coumarins. When $1 \mathrm{ml}$ of the methanol or aqueous extract was taken in test tube followed by few drops of $10 \%$ ferric solution was added. Formation of blue or green color indicates presence of phenols. For the steroids, $1 \mathrm{ml}$ of extract in chloroform and few drops of conc. $\mathrm{H}_{2} \mathrm{SO}_{4}$ was mixed to form brown ring. Fluorescence was detected by the UV test (365 $\mathrm{nm}$ ) for chloroform fraction which indicate the presence of coumarins. Flavonoids were verified for the studies chloroform, methanol and residual aqueous fraction with Shinoda test. In this test to the test solution few magnesium turnings and concentrated hydrochloric acid are added dropwise pink scarlet or green to blue color appears after minutes. The presence of saponins was confirmed by foamproducing properties of these compounds. They were identified in methanol and aqueous fractions.

Table 1 Results of phytochemical analysis of leaf extracts of SC. +++: Strong intensity reaction; ++: Medium intensity reaction; +: Weak intensity reaction; -: Nondetected.

\begin{tabular}{|l|l|l|l|l|}
\hline Entry & Phytochemicals & Hexane fraction & Chloroform fraction & Methanol fraction \\
\hline 1. & Phenols & - & + & +++ \\
\hline 2. & Saponins & - & - & +++ \\
\hline 3. & Steroids & + & +++ & + \\
\hline 4. & Flavonoids & - & + & - \\
\hline 5. & Coumarins & + & +++ & +++ \\
\hline 6. & Fatty acids & +++ & + & - \\
\hline
\end{tabular}

\section{Extraction yield}

Results of extraction yield showed that amount of extraction crude of SC depends upon the solvent nature and it varied from 10.2 to $41.0 \%$ with a descending order of methanol>water>chloroform $>$ hexane (Table 2). Extraction with methanol resulted in the highest amount of total extractable compounds whereas the extraction yield with hexane was small in comparison to other solvents. Higher extraction yield in methanol might be due to the fact that it easily penetrates the cellular membrane and extracts the intracellular ingredients from the plant material. These results showed that SC contains more of polar compounds than the others.

\section{Total phenolic content}

The quantitative determination of total phenol was determined with the Folin-Ciocalteu reagent. The total phenols were expressed as $\mathrm{mg} / \mathrm{g}$ gallic acid equivalent using the standard standard curve of gallic acid (Figure 1). Linearity of calibration curve was achieved between 1 to $8 \mu \mathrm{g} / \mathrm{ml}$ and calculated as equation: $y=0.0837 x-0.0513, R^{2}=0.999$, Where $y$ is absorbance at $760 \mathrm{~nm}$ and $\mathrm{x}$ is total phenolic content in the extracts and fractions. The maximum phenolic content was found in the methanol fractions $(86.2 \pm 2.6)$. In the hexane and chloroform fractions, phenolic compounds could not be detected. These results demonstrate clearly that the content of phenolic compounds is dependent on the polarity of the solvent used; higher the polarity of the solvent, higher the content of phenolic compounds. Moreover, SC leaves can be considered as a good source of phenolic compound.

\section{Antioxidant activity}

Most of the methods of determination of total antioxidant activity characterize the ability of the tested compound or product to scavenge free radicals where DPPH is the best example to measure the free radical scavenging activity. It is recommended for studies with electron and hydrogen donating compounds such as phenols or flavonoids. Our result showed that methanol fraction has highest percentage of phenol content. Keeping in view, we evaluated the antioxidant activity of ethanol extract and its fractions viz hexane, chloroform, methanol and aqueous by determining percentage inhibition of DPPH radical. Ascorbic acid was used as standard for present investigation. A significant inhibition of DPPH free radical was observed in ethanol extract and methanol fraction 
at the concentration of $100 \mu \mathrm{g} / \mathrm{ml}$ (Table 3). Ethanol extract inhibits $80.5 \%$ of the DPPH free radical at $100 \mu \mathrm{g} / \mathrm{ml}$ whereas methanol fraction showed $83.6 \%$ inhibition of DPPH radicals at the same concentration (Figure 2). These results were compared with ascorbic acid as standard drug which shows 92.1\% inhibitory activity. In addition, hexane and chloroform fraction were also evaluated for inhibition of DPPH radical but they have been found to show weak inhibitory activity.

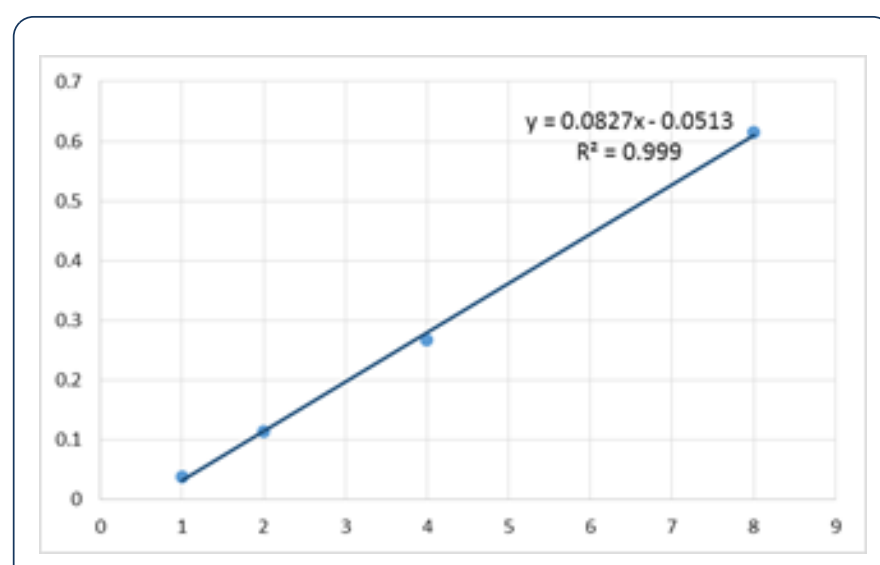

Figure 1 Standard curve of gallic acid.

Table 2 Extraction yield and Total phenolic content of SC leaves extracts. Values are mean \pm standard deviation of triplicate experiments. Different letters in columns show significant differences at $p<0.05$; ND: Not detected.

\begin{tabular}{|l|l|l|l|}
\hline S. No. & Solvent & Extraction yield $(\% w / w)$ & Total phenolic content (mg GAE/g extract) \\
\hline 1 & Ethanol & $10.0 \pm 1.5 \mathrm{a}$ & $81.8 \pm 3.4 \mathrm{a}$ \\
\hline 2 & Hexane & $10.2 \pm 0.5 \mathrm{~b}$ & ND \\
\hline 3 & Chloroform & $25.4 \pm 2.1 \mathrm{c}$ & $21.9 \pm 1.8 \mathrm{~b}$ \\
\hline 4 & Methanol & $41.0 \pm 1.8 \mathrm{~d}$ & $86.2 \pm 2.6 \mathrm{c}$ \\
\hline 5 & Water & $16.4 \pm 2.4 \mathrm{e}$ & ND \\
\hline
\end{tabular}

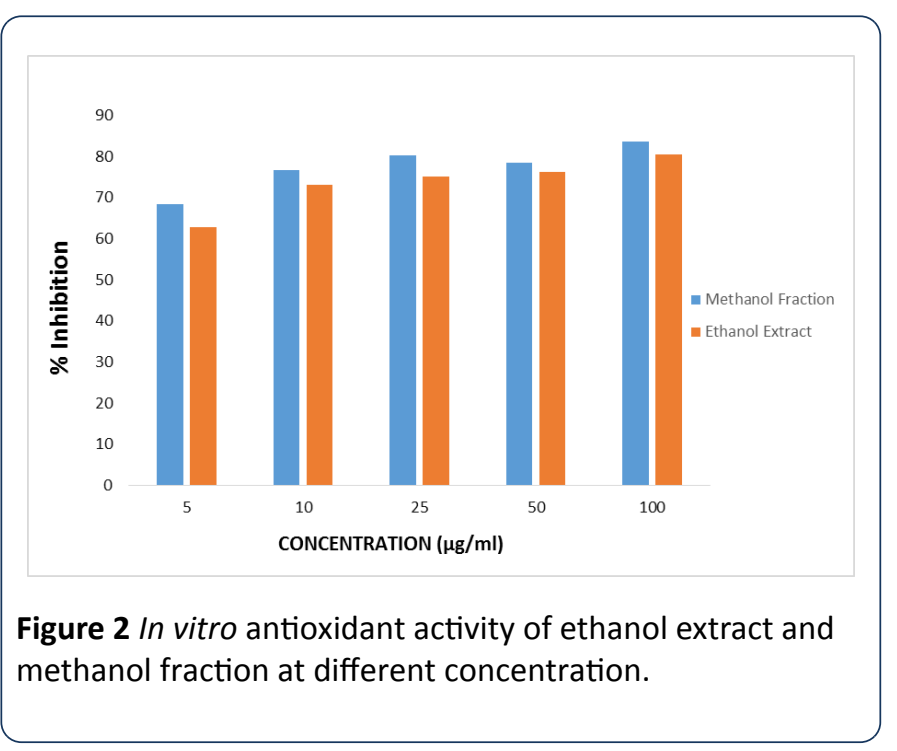

Table 3 DPPH assay showing \% inhibition of ethanol extract and its fractions. ND: not determine

\begin{tabular}{|l|l|l|l|l|l|l|}
\hline \multirow{2}{*}{ S. No. } & \multirow{2}{*}{ Concentration $(\boldsymbol{\mu g} / \mathrm{ml})$} & \multicolumn{2}{|l|}{} \\
\cline { 3 - 8 } & & Ethanol extract & Hexane fraction & Chloroform fraction & Methanol fraction & Aqueous fraction \\
\hline 1 & 5 & 62.8 & 20.1 & 25.6 & 68.3 & ND \\
\hline 2 & 10 & 73.1 & 21.7 & 27.4 & 76.6 & ND \\
\hline
\end{tabular}




\begin{tabular}{|l|l|l|l|l|l|l|}
\hline 3 & 25 & 75.1 & 21.9 & 30.8 & 80.2 & ND \\
\hline 4 & 50 & 76.2 & 24.5 & 32.7 & 78.5 & ND \\
\hline 5 & 100 & 80.5 & 29.3 & 35.1 & 83.6 & ND \\
\hline
\end{tabular}

\section{Antidiabetic activity}

Increased oxidative stress is involved in diabetes by the generation of oxygen derived free radicals. The generation of free radicals may lead to lipid peroxidation in diabetes mellitus by glucose degradation, non-enzymatic glycation of proteins and the subsequent oxidative degradation [14]. Glucose 6phosphatase is as hydrolyzing enzyme and plays a key role in the homeostatic regulation of blood glucose levels via formation of phosphate group and free glucose on hydrolysis [15]. Ethanol extract and all the fractions were evaluated for glucose-6-phaphatase inhibitory activity against standard drug sodium orthovanadate. Ethanol extract showed $51.3 \%$ inhibitory effect (Table 4). Furthermore, methanol fraction exhibited $57.9 \%$ inhibition of glucose-6-phosphatase enzyme at $100 \mu \mathrm{M}$ concentration which was most active in comparison to other fractions such as hexane, chloroform and aqueous fraction.

Table 4 In-vitro glucose-6-phosphatase enzyme inhibition results of extract and fraction at $100 \mu \mathrm{M}$ concentration. Percentage inhibition of sodium orthovanadate is $53.4 \%$ at $100 \mu \mathrm{M}$ concentration.

\begin{tabular}{|l|l|l|l|l|l|}
\hline \multirow{2}{*}{ S. No. } & \multicolumn{2}{|l|}{ \% inhibition of glucose-6-phosphatase enzyme } & Methanol fraction & $\begin{array}{l}\text { Aqueous } \\
\text { fraction }\end{array}$ \\
\cline { 2 - 6 } & Ethanol extract & Hexane fraction & Chloroform fraction & 57.9 & ND \\
\hline 1 & 51.3 & 25.1 & 33.5 & \\
\hline
\end{tabular}

\section{Conclusions}

In conclusion, our result shows the presence of various phytochemicals in fractions of plant which may be responsible for the pharmacological activity. Total phenolic content, antioxidant and antidiabetic activity were also discussed. Methanol fraction have highest phenolic content that is $86.2 \pm$ 2.6. Ethanol extract and methanol fraction shows maximum DPPH radical scavenging activity and they inhibit $80.5 \%$ and $83.6 \%$ free radicals at $100 \mu \mathrm{g} / \mathrm{ml}$ concentration, respectively. In order to antidiabetic activity, methanol fraction shows $55.5 \%$ inhibition of glucose-6-phosphatase enzyme. Extracts of SC appear to be attractive materials for further studies leading to possible drug development for antioxidant and diabetes which is relatively inexpensive, less time consuming and more economical for drug development and discovery.

\section{Acknowledgements}

Authors are highly grateful to EET (Era's Educational Trust), Era's Lucknow Medical College and Hospital, Lucknow, UP for financial assistance to carry out this work.

\section{Conflict of Interest}

The authors declare that there is no conflict of interests in respect to this study.

\section{References}

1. Petrovska BB (2012) Historical review of medicinal plants' usage. Pharmacogn Rev 6: 1-5.
2. Firenzuoli F, Gori L (2007) Herbal Medicine Today: Clinical and Research Issues. Evid Based Complement Alternat Med 4: 3740.

3. Ekor M (2013) The growing use of herbal medicines: issues relating to adverse reactions and challenges in monitoring safety. Front Pharmacol 4: 177-187.

4. Li JW, Vederas JC (2009) Drug discovery and natural products: End of an era or an endless frontier. Science 325: 161-165.

5. Brewer MS (2011) Natural Antioxidants: Sources, Compounds, Mechanisms of Action, and Potential Applications. Compr Rev Food Sci Food Saf 10: 221-247.

6. Takawira R, Nordal I (2003) The genus of Sansevieria (family Dracaenaceae) in Zimbabwe. Acta Hortic 552: 189-199.

7. Said A, Aboutabl EA, Melek FR, Jaleel GARA, Raslan M (2015) Steroidal saponins and homoisoflavanone from the aerial parts of Sansevieria cylindrica Bojer ex Hook. Phytochem Lett 12: 113-118.

8. Da Silva AA, Da Silva BP, Parente JP Valente AP (2003) A New Bioactive Steroidal Saponin from Sansevieria cylindrica. Phytother Res 17: 179-182.

9. Trease GE, Evans WC (1989) Pharmacology. Brailliar Tiridel and Macmillian Publishers, London.

10. Lin JY, Tang CY (2007) Determination of total phenolic contents in selected fruits and vegetables as well as their stimulatory effect on mouse splenocyte proliferation. Food Chem 101: 140-147.

11. Singh RP, Chidambara Murthy KN, Jayaprakash GK (2002) Studies on antioxidant polyphenol content of aqueous extract from pomegranate peel and seed extracts using in vitro models. J Agric Food Chem 50: 86-89.

12. Hubscher G, West GR (1965) Studies on the fractionation of mucosal homogenates from the small intestine. Nature 205: 799-800. 
13. Tussky HH, Shorr E (1953) A microcolorimetric method for the determination of inorganic phosphate. J Biol Chem 202: 675-685.

14. Gutierrez RP, Baez EG (2014) Evaluation of antidiabetic, antioxidant and antiglycating activities of the Eysenhardtia poylstachya. Phcog Mag 10: 404-418.
15. Ghosh A, Shieh JJ, Pan CJ, Sun MS, Chou JY (2002) the catalytic center of glucose-6-phosphatase. HIS176 is the nucleophile forming the phosphohistidine-enzyme intermediate during catalysis. J Biol Chem. 277: 32837-32842. 